\title{
SUBCLAVIAN-SUBCLAVIAN GRAFT IN OCCLUSIVE DISEASES OF THE NECK VESSELS
}

\author{
by A.K. Tayiem, M.D., F.A.C.S., F.I.C.S., Atchison, Kansas
}

\section{INTRODUCTION}

Stroke is the 3rd cause of death in the U.S.A., being preceded only by heart disease and cancer. It is estimated approximately 300,000 Americans suffer new strokes each year, that I/3rd of those with acute thrombotic strokes die within 30 days of onset, and that 200,000 people in the U.S.A. die yearly from this disease. There are alive today, in the U.S.A., two million people who have had strokes. The social and economic consequences to the nation and the lamilies of those individuals are incalculable.'

Increasing awareness of extra cranial location and segmented nature of atherosclerotic occlusive lesions in a large proportion of patients with cerebrovascular insufficiency has been followd by the development and use of removing or bypassing the offending plaques. It is now estimated that $75 \%$ of patients with ischemic stroke syndrome have at least one obstructive lesion at a surgically accessible site and that more than $40 \%$ have the principal occlusion confined to extra cranial vasculature. ${ }^{2}$

More than $75 \%$ of patients who suffer strokes have warning symptoms in the form of trans-ischemic attacks (TIAs). ${ }^{3}$ Likewise $30-35 \%$ of untreated patients with TIAs develop frank strokes if followed 3-5 years, or longer. 4 ,

\section{PATHOLOGY}

The Atheromatous Plaque consists of nodula deposition of fat, primarily cholesterol, in the arterial intima. There is associated inflammatory response resulting in libroblastic proliferation. Calcium salts may precipitate in the primary plaque. As the lesion enlarges, the central portion undergoes softening and may ruture through the over-lying intimal surface and result in a discharge of the atheromatous debris (emboli) into the lumen of the vessel. An open cavity remains in the central portion of the lesion. This cavity (ucler) can be the nidas for platelets aggregate or thrombous formation. Most frequently these aggregates are attached loosely and can be swept into the arterial stream as secondary emboli causing TlAs or frank strokes. Hemorrhage may occur within the soft portion of the atheromatous lesion and result in a precipitous extension of the lesion producing acute occulusion of the artery at that location."

Atheromatous lesions occur at branches or arterial bifurcations. The commonest location of significant lesions occurs at the carotid bifurcation. The ratio of extra-cranial to intracranial carotid lesions is $2101 .^{7}$

Stenosis of the carotid artery occurs in $34 \%$ of extra- cranial lesioins; while right vertebral artery is $8.4 \%$ and left vertebral artery $22.3 \%$ : the innominate artery $12.5 \%$ and the left subclavian artery is $12.4 \%$.

\section{CLINICAL MANIFESTATION}

The spectrum of symptoms in cerebrovascular disease can vary from minor episodes of neurologic dysfunction lasting less than 24 hours, to a major episode of cerebral infarction resulting in a permanent neurologic deficit.

Trans-lschemic Attack is defined as producing an episode of neurologic dysfunction that lasts no more than 24 hours and usually lasts just a few minutes following the attack. The patient returns to pre-attack status without residual neurologic deficit. TlA may produce lateralizing symptoms in which case their arterial origin and subsequent distribution can be labelled clearly. They also can produce generalized symptoms such as attoxia, dizziness, vertigo and syncope. which suggests a brain stem distribution or posterior circulation. Ischemic, however, these attacks cannot be labelled routinely due collateral to circulatory interrelationships of the carotid and vertebral basilar systems.

The subcla vian steal syndrome is one manifestation of vertebral-basilar insufficiency that occurs by way of an unusual manifestation of collateral circulatory redistribution. This abnormality was defined by Reivich et $\mathrm{al}^{8}$ in 1961 following an angiographic description in 1960 by Cantorni of retrograde flow in the involved vertebral artery.

When the origin of the subclavian artery becomes compromised, reversal of blood how occurs in the branches of the first portion of the subcla vian artery as well as the vertebral artery which can become a major collateral contributor for upper extremity blood flow; thus serving as a conduit through which the basilar artery blood flow may be siphoned off to calletoralize the upper extremity exercise.

The classic symptoms complex, associated with this syndrome, includes vertigo and/or pre-syncope flowing upper extremity exercise. Other symptoms include bilateral visual disturbance, dysarthria. disorder of equilibrium, impairment of consciousness and drop attacks. There may be monoparesis or paralysis shifting from side to side and involving any of the extremities.

Occlusion of the innominate artery may cause the same symptom complex in addition to symptoms of carotid insufficiency, since the reversal of blood llow occurs also via the carotid which include headaches, dizziness, blackout spells, loss of memory and buzzing 

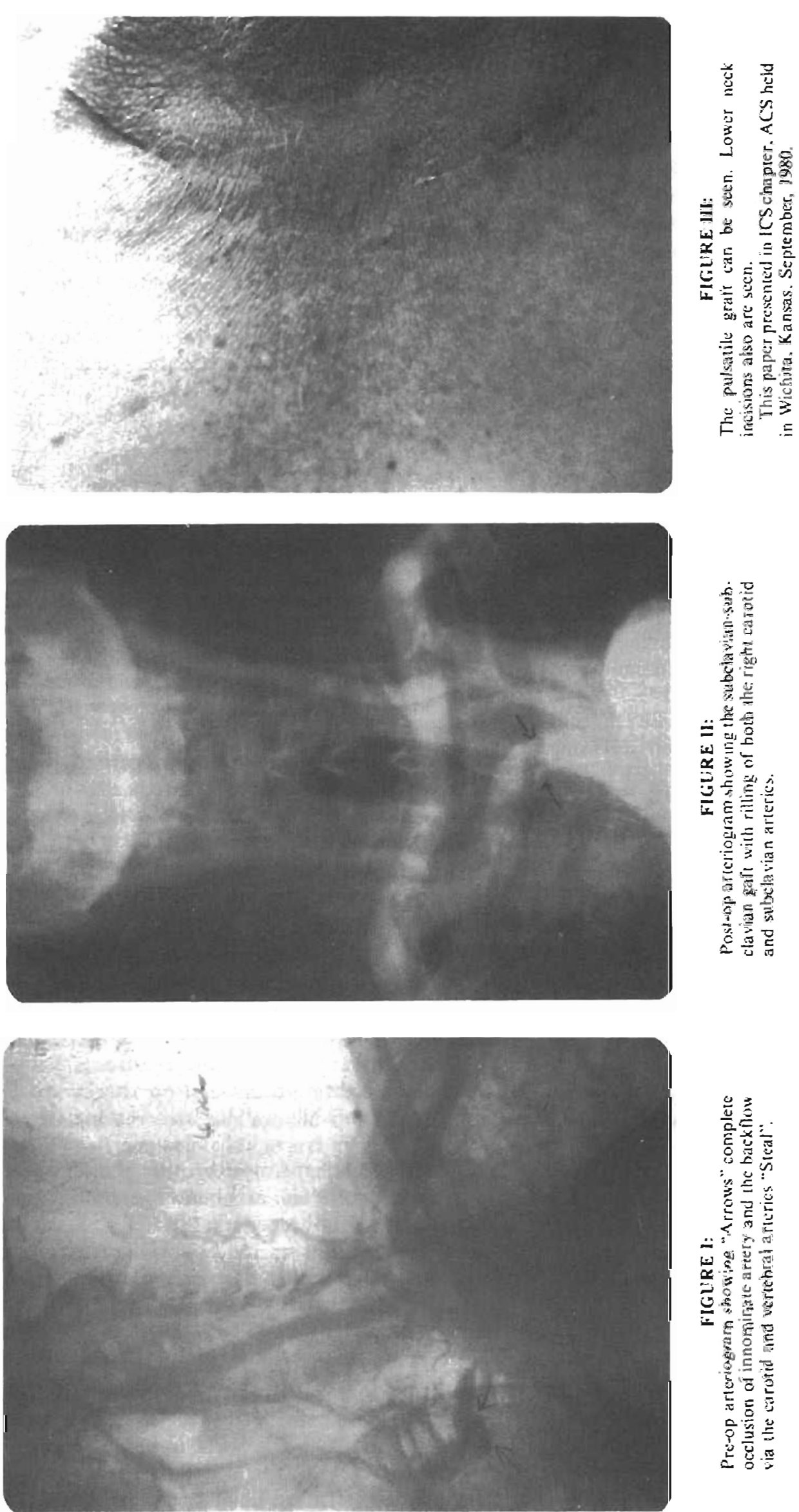
noises in head and ear.

It is significant to mention that a patient may demonstrate angiographic subclavian lesions without having any symptoms.

\section{EVALUATION OF PATIENTS}

A good history of the specific secuence of events involving neurologic dysfunction is the single most important sep in evaluation of paticnts who may have cerebrovascular insufficiency. Careful history review will be helpful in identifying other vascular occlusive diseases and risk factors. The following points are important in examination of these patients:

1. Bilateral upper extremity blood pressure. A difference in arm pressure may be the first clue to occlusive diseases of the arch vessels.

2. Peripheral pulses evaluation.

3. Determination of neck bruits in the a rea of carotid bifurcation and over the subclavian arteries.

4. Evaluation of the quality of neck pulses.

5. Neurologic examination.

6. Ophthalmic examination.

7. Other tests to evaluate internal carotid artery use Ophihalmosonometry (OSM). Ophthalmophethysmography and Ophthalmodynomometry. Brain scan and cerebral blood llow.

8. Angiography which visualizes all aortic branches and cercbral blood vessels as well as using substraction films.

The diagnosis of subclavian steal syndrome can easily be made by finding decreased pulse and blood pressure in the affected side in association with supraclavicular bruit. Serial angiogram can easily demonstrate the site of occlusion and the reversal blood flow to the affected site.

\section{TREATMENT}

Since the introduction in $1957^{\circ}$ of the extra-thoracic bypass grafts for occlusive lesions of the aortic arch branches, a noticeable decline in the operative mortality $(1 \%)$ and post operative morbidity (2-5\%). has been achieved when compared with direct intrathoracic approach.

Since then various authors have confirmed the effectiveness of various extra thoracic procedures. ${ }^{10} .11,12.1$ Various procedures have bcen used including carotid-subclavian, carotid-carotid. axillary-axillary. subclavian-vertebral and the most recent one carotid-veretebral by pass graft." The first report about using a subclavian-subclavian graft was by Ehrenfeld et al. 1968, in which they used a vein gratl. The graft was layed in front of the trachea and involving transection of Sterno Mestoid and scalenus anticus. The first series to report about subclaviansubclavian dacron grafi was by Norman Finkelstein et al." in which they reported their experience during 6 years and involving 13 patients. They retracted Sterno Mastoid and transected scalenus anticus on the affected side and placed the graft sub-cutaneously.

Searching the literature we could not find more reports about this procedure. We would like to make a plea for usage of this procedure more often because of the advantages it oflcrs. It is easier. less traumatic. less lime consuming, does not affect the carolid how during or after surgery and the graft is short and less affected by motion. The subclavian artery is not a fixed artery and can be mobilized from the neck without angulation of the graft.

This bypass graft can be used in occlusions of the left subclavian artery, innominate artery, right subclavian artery and vertebral artery. Other grafts can be connected $10 \mathrm{it}$, 10 carotid artcries and vertebral arteries as needed.

The carotid-subclavian bypass graft has the following disadvantages. It may siphon the blood from the distal ca rotid artery with subsequent decrease

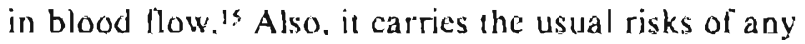
carotid surgery.

The axillary-axillary bypass gralt avoids the complications of carotid surgery but it is a longer procedure, and using a longer graft, with more wound complication and a greater potential for mal-position causing compression of the graft.

The carotid-carotid bypass which recently has been advocated. ${ }^{\text {th }}$ carries double risk of carotid surgery and should be preserved lor those rare cases of occlusion of innominate artery and left subclavian artery simultaneously.

We would like to report a case of right innominate artery occlusion using modified subclavian-subclavian dacron bypass graft.

CASE: 67 year old white male. complaining of weakness and numbness of left hand and forearm. cramps of right leg which started several months ago and progressively getting worse to the point where he is getting rest cramps. Palient was also complaining of dizziness, light-headedness, drop attacks and falling several times while walking and working around the house. Patient is a right handed person and has been using his right hand more because of weakness of left hand. Now he is experiencing more allacks of dizziness, light-headedness and drop atlacks. He noticed that his memory has been gelting poor recently. His medication conists of Hydropres $25 \mathrm{mg}$ iwice daily. Zyloprim $300 \mathrm{mg}$ daily and Vasodilan 20 mg 4 times daily.

Smokes cigareltes and drinks alcohol.

EXAM: Well nourished white male with the positive physical finding. B.P. right arm 70/?. left arm 150/86. Right carotid pulse is weak to absent. Right radial pulse is very weak. Right popliteal pulse is $1 / 4$. Left popliteal $3 / 4 \mathrm{rt}$. Post-tibial 0. left post-tibial 2/4. right 
dorsalispedis 0 . left dorsalispedis $2 / 4$. Doppler exam revealed right dorsalispedis and posterior tibial is $1 / 6$. Ischemic changes noticed on right foot. Left ulnar nerve paresis and parastheses in left hand and forearm are quite evident.

\section{TEST: Lipoprotein type II}

Nerve conduction test revealed left ulnar tunnel syndrome at the elbow. Cerebral blood flow revealed no perfusion within right side of neck and head in anteral phase.

Arteriogram revealed complete occlusion of the innominate artery at its origin and just distal to the bifurcation with reversed flow in the late arterial phase via the right carotid artery and right vertebral artery demonstrating the Subclavian Syndrome.

Arteriogram revealed complcte ocelusion of right superficial femoral artery with good popliteal trifurcation run off.

HOSPITAL COURSE: Patient underwent subclavian-subclavian $8 \mathrm{~mm}$ dacron graft without dividing either the Sterno Mastoid or scalenus anticus muscles and the graft was placed under the platysma. Hemodynamic equilibortion of bilateral arm blood pressure was observed to take place early in the recovery room. The Pulsatile graft was easily palpated. Patient dismissed in 7 days.

Patient underwent post operative arteriogram to evaluate graft position and patency and then underwent right femoro-popliteal reversed vein graft and left ulnar transposition from which he recovered well without complication.

TECHNIQUE: Pationt in supine. neck extonsion position. supraclavicular incisions are used along the medial 2/3rds of the clavicle.

Incision is earried through the skin the platysma, the anterior cervical fascia entered lateral to the sterno mastoid muscle. The scalenus anticus pad of fat is entered, mobilized to expose scalenus anticus muscle. Under the lateral border of this muscle and under the clavicle dissection will visualize the subclavian artery.

Two umbilical tapes pus around the subclavian artery, about $2 \mathrm{~cm}$ length of the artery is mobilized. The $8 \mathrm{~mm}$ Dacron grafi pre-clotted, anastomosed end to side to the artery - in the usual fashion.

A tunnel is made under the platysma to reach the other incision where the subclavian artery is ready for end 10 side anastomosis - systemic heparin. 5000 units are given $1 . V$. before doing the first duostemosis. No heparin given post. op. incisions closed in layers without drains.

There was no necd to transcel stcrno mastoid or scalenicur anticus as reported by previous author. The pulsatile gralt could be seen casily alter closure.

\section{SUMMARY}

Extra thoracic bypass grali is the preferred operation for stenotic lesions of the great vessels. Because of the excellent run off in most cases. these operations have very high immediate and long term rates of successful restoration of blood flow. Five year patency rate reported to be $80-90 \%$ and 10 year patuncy rate $60-70 \%$.

The subclavian-subclavian dacron grali should be used more often whenever it is indicated, because of its numerous advantages.

\section{REFERENCES}

1. Stallones, R.A., Dyken, M.C., Farg, H.C.H., Hayman. A. Report of the joint committee for stroke facilities. I: Epidemiology for stroke facilities planning. Stroke 3: 360, 1972.

2. Haswik, et al. Joint study of extra cranial a rterial occlusion. II: Arteriography, technique, sites and complications. JAMA 203: 961. 1969.

3. 'Thompson, J.E. Surgery for cercbrovascular insufficiency "stroke" (Springlield. IL, Charles E. Thomas, Publisher) 1968

4. Tool. J.F. et al. TIAS due to atherosclerosis. prospective study in 160 pts. Arch. Neural. 32:5. 1975.

5. Acheson, I., and Hutchison, E.C. The Natural History of Focal Cerebral Vascular Disease. Q.J. Med. 40:15. 1971.

6. Rutherford. Vascular Surgery, pg. I057. 1977. publisher.

7. Bluisdell. F.W. Hall. Ad. Cerebro Vascular Occlusive Disease, experience with pan arteriography in 300 conseculive cases California Med. 103:321. 1965.

Schwart\%. Principle of Surgery - 3rd edition.pg. 958. 1979. McGraw Hill, N.Y., publisher.

9. Croford. E.S., DeBakey, M.E.. el al. Surgical treatment of occlusion of the innominatc. common carotid and subclavian arteries. A ten year experience surg. 63:17. 1969.

10. Beebu. G. Hugh et al. Choices of Operations for subclavian-vertebral a rtery discase A M. J. Surg. 139:616, 1980.

11. Livesay, L. James et al. Late results of extra anotomic bypass grafts. Arch surg. I|4:1260. 1979.

12. Gulshan. K. Sethi et al. Extra thoracis bypass for stenosis of innominate artery. J. Thor. and cardio vasc. Surg. 69:2/2, 1975.

13. Finkelstein, Norman $M$. et al. Subclaviansubclavian bypass for the subclavian stecl syndrome. Surg. 71:142. 1972.

14. Malone, M.J. et al. Combined carotid vertebral disease Areh. Surg. 115:783. 1980.

15. Harper, J.A. et. al. An experimental hemodynamic study of subclavian steal syndrome. S.G. and O 124:1212, 1967.

16. Manart D. Frank et al. The carotid-carotid bypass grafe Arch surgery 115, 669, 1980. 